\section{Dynamic Compaction/Compression}

Fook-Hou Lee

National University of Singapore, Singapore, Singapore

\section{Definition}

A class of soil improvement methods that involves application of repeated impulsive loading onto the ground surface.

Dynamic compaction (DC) was originally developed for densifying loose granular fills and its effectiveness for such materials is well documented. The most common method of applying impulsive loading is by dropping a disk-shaped heavy mass with a weight of between 10 and 40 tonnes and a radius of between 2 and $4 \mathrm{~m}$, from a height of between 5 and $30 \mathrm{~m}$ (Lee and Gu 2004).

The primary mechanism causing densification are compressional ( $\mathrm{P}-$ ) waves generated by the impact of the falling weight on the ground. The passage of these waves causes a large, transient increase in effective stress, resulting in densification and plastic volumetric change of the soil ( $\mathrm{Gu}$ and Lee 2002). The passage of shear (S-) waves causing cyclic shearing may also have a secondary effect, but this is likely to be much less significant, since the number of cycles due to impulsive loading is often quite limited. Liquefaction has also been cited as an improvement mechanism, but this is probably a mistaken belief since DC works equally well in dry as well as saturated sand. The depth of improvement is often limited to about $10 \mathrm{~m}$ in granular soils owing to the tendency of the compressional waves to disperse laterally as they propagate downwards.

A typical DC program consists of two to three passes, each pass comprising a regular grid of DC "footprints" spaced about $3 \mathrm{~m}$ to about $8 \mathrm{~m}$ apart (Mayne et al. 1984, Lee and $\mathrm{Gu}$ 2004). Each footprint is generated by repeated dropping of the weights until the ground surface settlement stabilizes. The footprints are not contiguous. However, improvement is likely to be contiguous at greater depths owing to lateral dispersion of the stress waves. The second pass may involve similar or lower levels of impulsive loadings in a similar grid of footprints interspersed between the first grid. This pass is meant primarily to improve regions at intermediate depths and between the footprints from the first pass. The third pass is usually a light leveling pass for the near-surface regions and to level out the ground surface.

DC is often most effective in granular soils. However, there have also been cases of its successful usage on unsaturated clayey soils. It is normally not considered to be applicable to saturated clayey soils since the low permeability of the soil would prevent moisture egress from the soil skeleton during compaction. Although there have been a few reported cases of its use in saturated clayey soils, with vertical drains, its effectiveness is likely to be highly dependent upon the permeability of the soil. Clays with very low permeability are unlikely to be improvable by DC. One important consideration in the use of DC is the vibration from the impacts and its possible effect on surrounding structures and on archaeological remains within the ground. For this reason, DC is not often used in the vicinity of sensitive sites.

\section{Cross-References}

\author{
Compaction \\ $>$ Compression \\ Ground Preparation \\ - Soil Properties
}

\section{References}

Gu Q, Lee FH (2002) Ground response to dynamic compaction of dry sand. Geotechnique 52(7):481-493

Lee FH, Gu Q (2004) Method for estimating dynamic compaction effect on sand. J Geotech Geoenviron 130(2):139-152

Mayne PW, Jones JS, Dumas JC (1984) Ground response to dynamic compaction. J Geotech Eng 110(6):757-774 